\title{
ANALYSIS OF PLATELET INDICES IN TYPE 2 DIABETES MELLITUS PATIENTS WITH VASCULAR COMPLICATION
}

\author{
Nelly, Suci Aprianti, Darmawaty ER
}

Department of Clinical Pathology, Faculty of Medicine, Hasanuddin University /Dr. Wahidin Sudirohusodo Hospital, Makassar, Indonesia. Email:nellymashuri@gmail.com

\begin{abstract}
Type 2 Diabetes Mellitus (T2DM) is an endocrine disease that is marked by hyperglycemic condition due to a decrease of insulin secretion and/or insulin resistance. Indonesia is the 7th country with the highest incidence of diabetes mellitus in the world. Progression of the disease is slow and it causes vascular endothelial damage. The increase of platelet indices is suspected to be an indicator of vascular complications. This study aimed to evaluate the platelet indices in diabetic patients with complication and correlate these indices with GDP and HbAlc. Researchers analyzed platelet indices and biochemical data of patients in outpatients clinic of the Dr. Wahidin Soedirohusodo Hospitals. Total of 120 patients with type 2 diabetes mellitus were included with consisting of 64 patients with vascular complication and 56 patients without complication were involved in this study. Researchers observed an increase of Mean Platelet Volume (MPV), Platelet Distribution Width (PDW), but no increase of Plateletcrit (PCT) with value of $p=0.001, p=0.000$, and $p=0.168$, respectively. Researchers found a correlation between FBG and PDW ( $P=0.044)$. The study showed the significant differences of platelet indices (MPV and PDW) in patients with T2DM with and without complication, suggesting the presence of more reactive and aggregatable platelets in type 2 diabetes patients. This study suggested that platelet evaluation may be useful in the early detection of long term complication of diabetic patients.
\end{abstract}

Key word: T2DM, platelet indices, vascular complication

\section{INTRODUCTION}

Diabetes Mellitus (DM) is a group of chronic metabolic diseases characterized by high blood sugar level due to impaired insulin secretion and/or insulin resistance. ${ }^{1}$ In general, DM is classified into four types: type 1, type 2, a specific type of DM and gestational DM. The most common type is type 2 diabetes mellitus which comprises $80 \%$ of all diabetes cases. ${ }^{2}$

Diabetes mellitus cases are increasing every year in the world. Based on the International Diabetes Federation (IDF) data, the global prevalence of DM patients in 2012 was $8.4 \%$ of the world population and increased to 382 cases in 2013. Indonesia ranked as 7 th in countries with 8,5 million patients as the highest incidence of diabetes mellitus. ${ }^{3,4}$

Diabetes mellitus is a lifelong chronic disease. This disease will continue to progress and eventually lead to many complications. Epidemiologically, diabetes is often not detected, and it is now known that the onset of diabetes complications is about seven years after diabetes detected. Morbidity and mortality due to acute or chronic complications usually proceed slowly with mild to severe symptoms and even can result in death. ${ }^{5-7}$

The mechanism of vascular complications in DM is thought to be through several pathways, such as the Advanced Glycation End Products (AGEs), the polyol pathway, the protein kinase $C$ pathway, and the oxidative stress formation pathway. These four pathways cause vascular endothelial damage which results in activation of primary and secondary hemostasis pathways. ${ }^{8,9}$

Platelet is a blood component that plays a role in forming primary hemostasis blockage. This process begins with adhesion followed by aggregation. Platelets in DM patients express more P-selectin and GP IIb/IIIa receptors. Consequently, they become more sensitive to agonist stimuli compared to platelets in non-DM people. ${ }^{10}$

Vascular endothelial damage induces bone marrow to release immature platelets which are larger in size, more reactive, and aggregable, because they contain more dense granules, secrete more serotonin and $\beta$-thromboglobulin, and produce more thromboxane A2 than the smaller platelets. This is believed to be the reason for platelet changes in size, function, and activation in DM patients with vascular complications. ${ }^{9,10}$ 
Several studies suggested a correlation between platelet indices such as plateletcrit (PCT), Mean Platelet Volume (MPV) and Distributed Width Platelet (PDW)) in type 2 DM and vascular complications, as explained by Demirtunc and Duman, Jabeen, Fawwad. ${ }^{10,11}$ However, in a study by Hassan, it was found that there was no correlation between MPV values in type $2 \mathrm{DM}$ patients with and without complications. ${ }^{12}$

Hematological analysis using an automatic analyzer provides various platelet parameters that can help detect changes in the platelet index in the early detection of the occurrence of prothrombotic state. Therefore, authors werere interested in studying the platelet parameters in type 2 DM patients as the early detection parameters of vascular complications.

This study aimed to analyze platelet index values पDin type 2 DM patients with and without vascular complications. This research has been approved by the Health Research Ethics Committee of University of Hassanudin/Dr. Wahidin Sudirohusodo General Hospital with No.UH17070504.

\section{METHODS}

This study was performed using retrospective observational cross-sectional method and medical record data of type 2 DM patients from July 2016 to July 2017 in the Dr. Wahidin Sudirohusodo Hospital, Makassar. The inclusion criteria were type 2 DM patients who had been diagnosed by the clinician with complete medical record data, including platelet index results (MPV, PDW, and PCT). Type 2 DM patients with liver disease, HIV, malignancy, thyroid disorders, SLE, and bleeding disorder were excluded.

Platelet indices are result parameters of a routine blood test by measuring the PCT, MPV, and PDW values ulusing flow cytometry method and Pentra device. Patient data were grouped into type 2 DM without complications and with complications based on the clinician's diagnosis and the results of radiological examinations.

\section{RESULTS AND DISCUSSION}

This study collected the data from all type 2 DM patients medical records in one year period. The study samples consisted of 120 respondents who met the inclusion and exclusion criteria. 60 and 56 of them suffered from type 2 DM with complications and without complications, respectively. 46 and 74 of the respondents were male and female, respectively. Majority of the patients were within 50-60 years old (Table 1).

T-test showed that there was a significant difference of MPV values in type 2 DM patients with and without complications ( $p=0.001$ ) (Table 2 ).

T-test showed that there was a significant difference of MPV values in type 2 DM patients with and without complications ( $p=0.001$ ) (Table 3 ).

T-test showed no significant difference between PCT and platelet index values in type 2 DM patients with complications $(p=0.001)$ (Table 4).

Table 1. Characteristics of subjects

\begin{tabular}{lccc}
\hline Parameter & $\begin{array}{c}\text { DM without Complication } \\
\text { N/(Mean } \pm \text { SD) }\end{array}$ & $\begin{array}{c}\text { DM with Complication } \\
\text { N/(Mean } \pm \text { SD) }\end{array}$ & P-value \\
\hline Gender & $21(17.5 \%)$ & $25(20.83 \%)$ & \\
Males & $35(29.16 \%)$ & $39(32.50 \%)$ & \\
Females & $2(1.67 \%)$ & $1(0.83 \%)$ & \\
Age & $6(5.00 \%)$ & $11(9.10 \%)$ & \\
< 40 years old & $30(25.0 \%)$ & $31(25.83 \%)$ & \\
41-49 years old & $18(15.0 \%)$ & $21(17.5 \%)$ & \\
50-60 years old & $56 \pm 7.56$ & $57 \pm 8.83$ & 0.000 \\
$>$ >60 years old & $169 \pm 43$ & $228 \pm 84$ & $* 0.200$ \\
Age & $8.21 \pm 1.54$ & $10.7 \pm 2.2$ & 0.000 \\
FBG & $8.87 \pm 1.35$ & $9.46 \pm 1.99$ & $* 0.067$ \\
HbA1c & $12.36 \pm 2.81$ & $15.29 \pm 3.45$ & $* 0.068$ \\
MPV & $0.25 \pm 0.11$ & $0.28 \pm 0.14$ & 0.000 \\
PDW & & & \\
PCT & & & \\
\hline
\end{tabular}

Fasting Blood Glucose (FBG), Glycosylated Hemoglobin (HbA1c), Mean Platelet Volume (MPV), Platelet Distribution Width (PDW), Plateletcrit $(P C T), P$-value $($ Mean $\pm S D) *$ Normal data distribution $(P>0.05)$ 
Table 2. Analysis of MPV values differences in type 2 DM with and without complications

\begin{tabular}{lccccc}
\hline \multirow{2}{*}{ Category } & \multirow{N}{*}{$\mathbf{N}$} & \multicolumn{3}{c}{ MPV Value } & \multirow{2}{*}{ P } \\
\cline { 3 - 5 } & & Min/Max & Mean+SD & Median & \multirow{2}{*}{$0.001^{*}$} \\
\hline DM without complication & 56 & $6.7 / 12$ & $8.87 \pm 1.35$ & 8.85 \\
DM with complication & 64 & $7.0 / 19.5$ & $9.96 \pm 1.99$ & 9.60 & \\
\hline
\end{tabular}

SD: Standard Deviation. * t-test. MPV: Mean Platelet Volume (N=6.5-11 m3)

Table 3. The PDW values of type $2 \mathrm{DM}$ patients with and without complications

\begin{tabular}{|c|c|c|c|c|c|}
\hline \multirow{2}{*}{ Category } & \multirow{2}{*}{$\mathbf{N}$} & \multicolumn{3}{|c|}{ Value PDW } & \multirow{2}{*}{$\mathbf{P}$} \\
\hline & & Min/Max & Mean+SD & Median & \\
\hline DM without complication & 56 & $8 / 18$ & $12.36 \pm 2.81$ & 12.3 & \multirow{2}{*}{$0.000 *$} \\
\hline DM with complication & 64 & $8 / 26$ & $15.29 \pm 3.45$ & 15.3 & \\
\hline
\end{tabular}

SD: Standard Deviation. * t-test. PDW: Platelet Distribution Width (N: $10-18$ fl)

Table 4. Analysis of PCT values in type 2 DM patients with and without complications

\begin{tabular}{cccccccc}
\hline \multirow{2}{*}{ Variable } & \multicolumn{2}{c}{ MPV } & \multicolumn{2}{c}{ PDW } & \multicolumn{2}{c}{ PCT } & P \\
\cline { 2 - 7 } & $\mathbf{r}$ & $\mathbf{p}$ & $\mathbf{r}$ & $\mathbf{p}$ & $\mathbf{r}$ & 0.252 \\
GDP & 0.097 & 0.292 & 0.184 & $* 0.044$ & 0.105 & 0.570 \\
HbA1c & 0.024 & 0.796 & 0.145 & 0.115 & 0.052 & \\
\hline
\end{tabular}

SD: Standard Deviation. *t-test. PCT: Plateletcrit (N: $0.15-0.50 \%)$

Table 5. Analysis of correlation between FBG and HbA1c with platelet index in type 2 DM patients

\begin{tabular}{|c|c|c|c|c|c|}
\hline \multirow{2}{*}{ Category } & \multirow{2}{*}{$\mathbf{N}$} & \multicolumn{3}{|c|}{ PCT Value } & \multirow{2}{*}{$\mathbf{P}$} \\
\hline & & Min/Max & Mean+SD & Median & \\
\hline DM without complication & 56 & $0.00 / 0.70$ & $0.25 \pm 0.12$ & 0.240 & \multirow[t]{2}{*}{0.168} \\
\hline DM with complication & 64 & $0.0 / 0.80$ & $0.28 \pm 0.14$ & 0.250 & \\
\hline
\end{tabular}

r: correlation, P-value: Mean+SD, Spearman rho

Rho test showed that there was a correlation between $\mathrm{HbAlc}$ and PDW values in type $2 \mathrm{DM}$ patients with correlation value 0.184 and $p=0.044$. However, there was no correlation between the FBG level and other platelet indexes. It was also shown that $\mathrm{HbA1c}$ was not related to platelet index value (Table 5).

This research was carried out from July to August 2017 by collecting medical record data from July 2016 to July 2017 in the Dr. Wahidin Sudirohusodo Hospital, Makassar. The study used a retrospective cross-sectional method involving 120 respondents who met the inclusion and exclusion criteria. Prevalence of type 2 DM was higher in females with the highest age prevalence was within the range of 50-60 years old. The independent t-test results showed significant difference of platelet index values, MPV and PDW in type 2 DM patients with and without complications.

This result was consistent with the results reported by Luthfullah et al. that detected an increase of MPV value in type 2 DM patients. Another study by Karmilla et al. also reported an increase of MPV, PDW, PCT, and platelet index values as vascular complication markers in patients with type 2 diabetes. ${ }^{9}$

The MPV indicated the average size of platelet as a marker of platelet activity. In DM patients, there were morphological and functional change of platelet. The platelets type 2 DM patients showed higher expression off P-selectin and GP IIb/IIIa receptors resulting in increased sensitivity to agonist stimuli compared to platelets in non-DM subjects. ${ }^{7,8}$

Platelet hyperactivity is characterized by platelet morphological change into a spherical form, the formation of pseudopodia and release of immature platelets from bone marrow which are larger in size, more reactive and aggregable. Larger and immature platelets contain more dense granules, increased secretion of serotonin and $\beta$-thromboglobulin. They also produce more thromboxane $A 2$ compared to smaller platelets. This results in more various platelet 
sizes which are marked by the increase of PDW, another platelet index markers. ${ }^{9,13}$

There are some opinions suggesting that platelet index parameters such as MPV, PDW and platelet count cannot be separated as the indicators of platelet activity. In this study, the PDW values in type 2 DM patients with complications was higher than in type $2 \mathrm{DM}$ without complications. This result was consistent with the result of a study by Jabeen et al. who described the role of platelet index in type 2 DM with vascular complications by suggesting a significant correlation between platelet indices in type $2 \mathrm{DM}^{10,13}$

In this study, there was no difference between the value of PCT in type 2 DM patients with and without complications. This was not corresponding with the research by Karmila et al. that found a difference in the value of PCT in type 2 DM patients with and without complications. Complications of type $2 \mathrm{DM}$ are thought to begin with change of platelets size to be larger and more reactive followed by an increase of platelet counts due to increased platelet consumption so that the value of PCT will also increase. $^{6,10}$

This study also found a correlation between FBG levels and PDW values with $p<0.05$ and a correlation value of 0.184 . This finding was consistent with the research by Thomas that showed a correlation between MPV and GDP and HbA1c. Hyperglycemia in DM is caused by impaired insulin secretion and/or insulin resistance causes vascular endothelial damage. ${ }^{13}$

Platelets have an important role in primary hemostasis such as response to repair endothelial damage, changes of platelet shape, attachment to the endothelium and release of intracellular organelles, aggregate and thrombus formation. These all will result in an increased of PDW values. Further analysis of this study was necessary to identify whether hyperglycemic conditions can reduce platelet activity in order to prevent or delay the possibility of diabetic vascular complications. ${ }^{9,11}$

The limitation of this study was the hematological data in the medical records were taken at the end of the visit. Consequently, the data were possibly influenced by several factors such as type of diabetes therapies, anticoagulant therapies and the length of time a patient has the type $2 \mathrm{DM}$, and its complications.

\section{CONCLUSION AND SUGGESTION}

There were differences in the average platelet index values of MPV and PDW in complicated and uncomplicated type 2 DM patients with no PCT increase. The MPV and PDW values were higher in complicated type 2 DM patients than uncomplicated type 2 DM. This was caused by hyperglycemia leading to platelet hyperactivity as the beginning of the procoagulant state. Poor glycemic control will result in various platelet size.

Further researches were needed to determine the use of platelet index can as an early marker of the occurrence of vascular complications and to determine more factors causing changes of platelet index in type $2 \mathrm{DM}$ patients.

\section{REFERENCES}

1. PERKENI. Konsensus pengendalian dan pencegahan DM tipe 2 di Indonesia. Jakarta, PERKENI, 2015; 1-78.

2. Purnamasari D. Diagnosis dan klasifikasi diabetes melitus. Dalam buku ajar ilmu penyakit dalam. Edisi VI., Jakarta, Pusat Penerbitan Ilmu Penyakit Dalam FKUI. 2014; 2323-7.

3. American Diabetes Association. Diagnosis and classification of diabetes. Diabetes Care, 2012; 35(1): S64-S71.

4. International Diabetes Federation (IDF) Atlas Group. Diabetes atlas. Sixth Ed., Diabetes Res Clin Pract, 2013; 51-68.

5. Riset Kesehatan Dasar. Badan penelitian dan Pengembangan Kesehatan. Jakarta, Kementrian Kesehatan Republik Indonesia, 2013; 87.

6. Wild S, Roglic G, Green A, Sicree R, King H. Global prevalence of diabetes: Estimates for the year 2000 and projections for 2030. Diabetes Care, 2004; 27 : 1047-1053.

7. Kamilla R. Are thrombocyte indices useful in the evaluation of type 2 diabetic patients?. J. Bras Patol Med Lab, 2016; 52(2): 96-102.

8. Ekici B, Erkan AF, Alhan A, Sayin I, Ayli M, Töre HF. Is mean thrombocyte volume associated with the angiographic severity of coronary artery disease? Kardiol Pol. 2013; 71(8): 832-8.

9. Park BJ, Shim JY, Lee HR, Jung DH, Lee JH, Lee YJ. The relationship of thrombocyte count, mean thrombocyte volume with metabolic syndrome according to the criteria of the American Association of Clinical Endocrinologists: A focus on gender differences. Thrombosis, 2012; 23(1): 45-50.

10. Jabeen F, Fawwad A, Rizvi HA, Alvi F. Role of thrombocyte indices, glycemic control and hs-CRP in pathogenesis of vascular complications in type-2 diabetic patients. Pak J Med Sci. 2013; 29(1): 152-6.

11. Demirtunc, Duman, Basar M. The relationship between glycemic control and thrombocyte activity in type 2 diabetes mellitus. J Diabetes Complications, 2009; 23(2): 89-94.

12. Hasan Z. Zubair Hasan. Assessment of mean platelet volume in type 2 diabetes mellitus and prediabetes. Natl J Lab Med, 2016; 5(3): PO54-PO7. 
13. Vagdatili E, Gounari E, Lazaridou E, Katsibourlia E, Tsikopoulou F, Labrianou I. Platelet distribution width: A simple, practical and specific marker of activation of coagulation. Hematology Laboratory, General Hospital of Florina, Greece. Hipocratia, 2010; 14(1): 28-32.
Alex KT, Udaya KM, Suraksha BR, Mothakapalli TJ, Madhavi $\mathrm{R}$, et al. Mean Platelet Volume in type 2 diabetes mellitus. Department of Pathology, Sri Devaraj Urs Medical College, Tamaka, Kolar, India, 2012 